\title{
CD24 gene inhibition and TIMP-4 gene upregulation by Imperata cylindrica's root extract prevents metastasis of CaSki cells via inhibiting PI3K/Akt/snail signaling pathway and blocking EMT
}

Paul Nayim $^{a, b}$, Armelle T. Mbaveng ${ }^{a}$, Mukherjee Sanjukta $^{b}$, Jain Rikesh ${ }^{c}$, Victor Kuete ${ }^{a}$, Krishna Sudhir ${ }^{b}$

${ }^{a}$ Department of Biochemistry, University of Dschang, Dschang, Cameroon;

${ }^{b}$ National Centre for Biological Science - Tata Institute for Biological Research, Bangalore, India;

${ }^{c}$ Aix-Marseille Université - CNRS UMR 7288, Institut de Biologie du Développement de Marseille, Laboratoire de Chimie Bactérienne UMR 7283 and Turing Center for Living Systems. Marseille, France.

Correspondence to:

*Mukherjee Sanjukta; Bellary Road, Bangalore 560065, India; email: msanjukta10@gmail.com;

**Victor Kuete; P.O. Box. 1499 Bafoussam, Cameroon; email: kuetevictor@yahoo.fr

\section{Other authors emails:}

Paul Nayim: nayimpaul@yahoo.fr

Armelle T. Mbaveng : armkuete@yahoo.fr

Jain Rikesh: rikeshjain44@gmail.com

Krishna Sudhi: skrishna@ncbs.res.in 


\section{Abstract}

Ethnopharmacological relevance. Imperata cylindrica (L.) Raeusch (Gramineae) is a medicinal spice traditionally used in the treatment of hypertension and cancer.

Aim of the study: To assess the anti-metastatic potential of the methanol extract of $I$. cylindrica roots and determined its mechanisms of action.

Material and methods. the growth inhibition activity of I. cylindrica root extract in vitro and in vivo in human cervical cancer. The scratch assay and Boyden Chamber assay were used to determine the anti-migrative and anti-invasion actions of the plant extract. The wholegenome gene expression profiling using RNA-Seq was performed to determine the differentially expressed genes in CaSki cells after exposure to I. cylindrica to identify its targeted genes related to metastasis. Using protein analysis (western blotting) and gene expression analysis (RTqPCR), the targeted pathways of the key genes that were initially identified with RNA-Seq, were evaluated.

Results. I. cylindrica extract showed dose-dependent cytotoxicity in vitro and in vivo in mice bearing tumors. Furthermore, I. cylindrica root extract significantly inhibited cell migration and cell invasion. After the genome-wide transcriptome analysis, we found that important genes involved in cancer progression and metastasis of cervical cancer, that is, CD24 and TIMP-4 were significantly downregulated and upregulated, respectively. Moreover, $I$. cylindrica root extract significantly inhibited the PI3/AKT/Snail signalling pathway and blocked the EMT of CaSki cells.

Conclusion. These findings provide an anti-metastatic mechanism of action of I. cylindrica root extract toward the human cervical cancer suggesting that this plant maybe developed into selective chemotherapy.

Keywords: Imperata cylindrica; Anti-metastatic activity; CD24; TIMP-4; PI3K/AKT; EMT. 


\begin{abstract}
Abbreviations
AKT (PKB), Protein kinase B; CD24, Cluster of Differentiation 24; DMEM, Dulbeco's modified eagle medium; EMT, Epithelial-mesenchymal transition; FBS, foetal bovin serum; MMP, Matrix metalloproteinase; MT1-MMP, Membrane type-1- Matrix metalloproteinase; NAD(P)H, Nicotinamide adenine dinucleotide phosphate; NSG, NOD scid gamma mouse; PBS, phosphate-buffered saline; PI3K, Phospoinositide 3-kinase; TIMP-4, tissue matrixmetalloproteinase Inhibitor-4;
\end{abstract}

\title{
1. Introduction
}

Cancer is a broad term describing a group of diseases mainly characterised by uncontrolled cell division because of malfunctions of the regulatory mechanisms that oversee the cell growth and development. Despite significant progress in modern cancer research, cancer remains a major threat to human life. An estimated number of 18.1 million new cancer cases were diagnosed in 2018 and 9.6 million patients died because of cancerous diseases. Among all the cancer diagnosed, cervical cancer is one of the major causes of cancer related death in women worldwide, with more than 500,000 new cases diagnosed in 2018 (Bray et al., 2018). Most often, women become susceptible to developing cancer of the cervix following HPV infection, but other environmental factors are also required for cancer to develop (Crosbie et al., 2013). At advanced stage, malignant cervical cells can break off from the primary tumor and spread through the blood stream or lymph vessels to the lungs, liver, brain and bones, which is known as metastasis, commonly called stage IV cancer (Li et al., 2016). Epithelialmesenchymal transition (EMT) has been recognised as an important event to support the metastatic ability of cancer cells (Heerboth et al., 2015). Metastasis is the primary cause of death in patients suffering from cancer (Steeg, 2016), and in most of the cases, metastasis represent one of the main reasons for treatment failure (Qian et al., 2017). Cervical cancer 
patients are treated with a combination of radiation and chemotherapy; unfortunately one of the most critical problems associated with cancer treatment is the resistance developed by cervical tumors against these therapies: Pranatharthi et al. (2019) studied the molecular pathways in cervical tumors and found that some cells of the tumor, which are resistant to radiotherapy, have increased expression of a particular protein (RhoC) leading to enhanced DNA repair in cells exposed to radiation. Therefore, search and development of new drugs effective against primary cancers as well as able to inhibit metastasis will be of great benefit to patients suffering from early-stage cancer and those with advance stage cancer. Natural plant-derived compounds are a leading source of drug development (Newman, 2012; Unnati et al., 2013), and some popular anticancer drugs such as taxol or paclitaxel are planted derived molecules. In this study, we thus decided to focus on Imperata cylindrica, a perennial rhizomatous grass commonly known as "cogon grass", native to Southeast Asia, widely distributed in Africa, Asia, Australia, Europe, North America, and South America (Hubbard et al., 1944). The roots of I. cylindrica, have been described in traditional herbal medicine in the treatment of hypertension (Park, 2004) and cancer (Kuete et al., 2013). A Previous study on this specific plant, shown its antibacterial activity (Voukeng et al., 2012), antifungal properties (Dzoyem et al., 2014) and anti-trypanosomal properties (Oyindamola et al., 2012); Kwok et al. (2016) showed the cytotoxic and pro-oxidative effects of ethyl acetate extract Imperata cylindrica's aerial part in colorectal cancer. Whereas many pharmacologically active compounds have been isolated from the roots of I. cylindrica such as arundoin, cylindrin, fernenol, cylindol, cylindrene, graminones and imperanene (Matsunaga et al., 1994a; Matsunaga et al., 1994b; Matsunaga et al., 1994c; Matsunaga et al., 1995). Despite previous studies on the anti-proliferative activity of $I$. cylindrica crude extract, there is no reported study of its antitumor effect on human cervical cancer. Hence, this study aimed at investigating the cytotoxicity of the methanol root extract of $I$. cylindrica on a panel of 
human cervical cancer cells and to highlight its anti-migratory and anti-invasive effects, as well as the mechanism of action against the metastatic cell line CaSki.

\section{Materials and methods}

\subsection{Chemicals}

Dulbeco's Modified Eagle medium, foetal bovin serum, nutrient mixture, penicillin, and streptomycin were purchased from Gibco, Thermo Fisher Scientific (MO, USA). Hydrocortisone, Toxin cholera, epidermal growth factor and adenine were supplied by Sigma-Aldrich (Bangalore, India). Y-27632 was provided by Calbiochem (Bangalore, India). Insulin was obtained from Invitrogen BioServices (Bangalore, India). Tween 20 and trypsin/EDTA were supplied by Gibco (Canada). WST-1 was purchased from Sigma-Aldrich (Roche Diagnostics, Germany), and cisplatin was obtained from Celon Laboratories (India). Matrigel was purchased from Corning (Corning). Dimethyl-sulfoxide, formaldehyde and mitomycin were obtained from Sigma-Aldrich (St Louis, USA). The ELC chemiluminescence kit was purchased from Cell Signaling Technology (USA). The Bradford protein assay kit and Laemeli sample buffer were supplied by Bio-Rad (USA). Trizol was obtained from Ambian Life Technology, Thermo Fischer Scientific (USA). The SuperScript

III cDNA synthesis kit was purchased from Invitrogen (USA). Antibodies were from Cell Signaling Technology (Santa Cruz, USA) and primers were all purchased from Sigma (India).

\subsection{Plant metabolites extraction}

The roots of I. cylindrica were harvested in the "Menoua" Division in the West Region of Cameroon Region $\left(5^{\circ} 27^{\prime} \mathrm{N} / 10^{\circ} 04^{\prime} \mathrm{E}\right)$. A sample of this plant was identified and authenticated by Mr. NANA Victor at the National Herbarium of Cameroon (Yaounde) as Imperata 
cylindrica (L.) Raeusch (Gramineae) under the voucher number 30139/SRF-Cam. The roots of I. cylindrica were dried and ground; the resulting powder was macerated in methanol $(1: 3$ w/v) at room temperature for $48 \mathrm{~h}$ and filtered with Wattman $\mathrm{N}^{\circ} 1$ paper and the filtrate obtained was evaporated using a rotary evaporator (BÜCHI R - 200) at $65^{\circ} \mathrm{C}$. The crude extract was recovered in a sterile vial and dried in an oven at $40^{\circ} \mathrm{C}$ until the trace of extraction solvent completely evaporated. Afterward the resulting product was dried using a lyophilizer (Labconco Freeze dryer $-105^{\circ} \mathrm{C}$, Thermofisher, USA) and stored at $-20{ }^{\circ} \mathrm{C}$ until further use.

\subsection{Cell line and cell culture}

The human cervical cancer cell lines $\mathrm{CaSki}$ and $\mathrm{SiHa}$ were purchased from the American Type Culture Collection (ATCC, Rockville, MD, USA). The cells were maintained in Dulbeco's Modified Eagle Medium supplemented with $10 \%$ foetal bovin serum and 1\% Penicillin and Streptomicin $(10 \mathrm{~mL} / \mathrm{L})$. The Human normal cervical cell line HCK1T (ATCC, Rockville, MD, USA) was maintained in 3:1 (v/v) Nutrient Mixture - Dulbeco's Modified Eagle Medium supplemented with 5\% FBS, $0.4 \mu \mathrm{g} / \mathrm{mL}$ hydrocortisone, $5 \mu \mathrm{g} / \mathrm{mL}$ insulin, $8.4 \mathrm{ng} / \mathrm{mL}$ toxin cholera, $10 \mathrm{ng} / \mathrm{mL}$ epidermal growth factor, $24 \mathrm{ng} / \mathrm{mL}$ adenine and 5 $\mu \mathrm{mol} / \mathrm{mL}$ Y-27632. All cells were incubated in a humidified atmosphere of $5 \% \mathrm{CO}_{2}$ at $37^{\circ} \mathrm{C}$. The cells were passaged twice or trice weekly and all experiments were performed with cells in the logarithmic growth phase.

\subsection{Animals}

The therapeutic activity of I. cylindrica root extract was investigated using 6 to 8 weeks-old (20-25 g) female NSG (NOD scid gamma mouse) obtained from the Animal Care and Resource Centre (ACRC) of the National Centre for Biological Science (NCBS)-TIFR. Mice were maintained in standard cages under sterile conditions, with air filter tops and in a laminar air flow room, temperature of $22^{\circ} \mathrm{C}$, and a under $12 \mathrm{~h} \mathrm{light/dark} \mathrm{schedule.} \mathrm{Rodent}$ 
diet and water were provided ad libitum. All animal procedures were approved and operated according to the National Centre for Biological Science (NCBS)-Institutional Animal Ethics Committee (IAEC) under the research project's IAEC approval number NCBS-IAE2019/13(N).

\subsection{Cytotoxicity assay}

The cytotoxicity of the root methanol extract of I. cylindrica toward SiHa, CaSki and HCK1T cell lines was performed using the cell proliferation reagent WST-1. The stable tetrazolium salt WST-1 is cleaved to a soluble formazan by a complex cellular mechanism that occurs primarily at the cell surface. This bio-reduction is a largely dependent dye formed directly on the glycolytic production of $\mathrm{NAD}(\mathrm{P}) \mathrm{H}$ in viable cells. Therefore, the amount of formazan dye formed directly correlates to the number of metabolically active cells in the culture. To do so, briefly, cells were detached by treatment with $0.5 \%$ trypsin/EDTA and seeded at a density of $6 \times 10^{3}, 7 \times 10^{3}$ and $15 \times 10^{3}$ cells/well of a 96-well cell culture plate (Greiner, bio-one, Cellstar, Germany) respectively for $\mathrm{SiHa}, \mathrm{CaSki}$ and HCK1T for a total volume of $100 \mu \mathrm{L}$; cells were allow to attached overnight. Afterwards, they were immediately treated with different concentrations of the plant extract ranging from 3 to $384 \mu \mathrm{g} / \mathrm{mL}$, dissolved in $0.1 \%$ Dimethyl-sulfoxide and incubated for 24, 48 and 72h; cisplatin was used as a positive control. After the incubation periods, $10 \mu \mathrm{L}$ of WST-1 reagent was added to each well and incubated for $1 \mathrm{~h}$. Absorbance was measured at $450 \mathrm{~nm}$ wavelength (Spectra-Max M5 Multimode reader). Each assay was performed in triplicate and repeated at least three times, the viability was evaluated with respect to untreated cells and the $\mathrm{IC}_{50}$ value was defined as the sample concentration required to inhibit $50 \%$ of cell proliferation.

\subsection{Wound healing assay}


To assess the effect of I. cylindrica root extract on CaSki cell migration (2D), a number of $3 \times 10^{5}$ CaSki cells / well were seeded onto a 12-wells cell culture plate (Greiner, bio-one, Cellstar, Germany) overnight to reach a $95 \%$ confluency monolayer. The cells were then treated with $2 \mu \mathrm{g} / \mathrm{mL}$ of mitomycin for $2 \mathrm{~h}$ to arrest cell proliferation, afterward a "scratch" was made in the cell monolayer using a $200 \mu \mathrm{L}$ pipette tip to create a wound. The detached cells were washed out using phosphate-buffered saline (PBS). Excepted for the control made up of the same number of cells and equal concentration of DMSO (0.1\%) used for drug dissolution, all wells were treated with five different concentrations of I. cylindrica root extract chosen below its $24 \mathrm{~h} \mathrm{IC}_{50}$ value, i.e. $15,30,40,50$, and $60 \mu \mathrm{g} / \mathrm{mL}$. In the same field, the wound distance was measured before and after incubation (16h), under IX 73 Olympus inverted fluorescence microscope at $4 \mathrm{X}$ magnification (Cairn, Kent, UK) to evaluate wound closure. Wound healing was analysed using ImageJ software (National Institute of Health, USA). Experiments were carried out in triplicate and repeated at least three times.

\subsection{Boyden chamber assay}

To assess the effect of $I$. cylindrica root extract on CaSki cell migration (3D) and invasion, we carried out a Boyden chamber assay using 12-well transwell chambers.

\subsubsection{Transwell migration assay}

Briefly, CaSki cells were seeded into a 6-well plate, after they reached confluency, cells were serum starved for $24 \mathrm{~h}$. Next day, cells were trypsinized and $1 \times 10^{5}$ of them resuspended in $250 \mu 1$ of DMEM at $1 \%$ FBS were seeded in the upper chambers of the transwell insert $(6.5$ diameter, $8.0 \mu \mathrm{m}$ pore size, PET membrane, Costar, Kennebunk, USA). Except for the control, all the cells were treated with different concentrations of the plant extract $(15,30,40$, 50 and $60 \mu \mathrm{g} / \mathrm{mL}$ ) chosen below its $24 \mathrm{~h} \mathrm{IC}_{50}$ value. The lower chambers were filled with 750 $\mu \mathrm{L}$ DMEM with $10 \%$ FBS. The cells were allowed to migrate for $24 \mathrm{~h}$, afterward they were 
washed twice with PBS and fixed with $4 \%$ formaldehyde for $15 \mathrm{~min}$. Following this, formaldehyde was removed, cells were washed twice with PBS and permeabilized at RT for 20 min using $100 \%$ methanol. After permeabilization, the cells were again washed twice with PBS and stained with $0.2 \%$ crystal violet, incubated for 15 min at RT and washed with PBS. The non-migratory cells were removed from the top aspect of the membrane using cotton buds. For their quantification, cells were imaged under a Nikon Inverted Microscope ECLIPSE TE2000-S and counted using ImageJ software. All assays were performed at least three times.

\subsubsection{Transwell invasion assay}

Briefly, cells were plated in 6-well plates, serum starved for $24 \mathrm{hrs}$ and the next day, they were trypsinized. The upper chamber of the transwell insert (6.5 diameter, $8.0 \mu \mathrm{m}$ pore size, PET membrane, Costar, Kennebunk, USA) was coated with $100 \mu \mathrm{L}$ mixture (1:6) of Matrigel - PBS and dried for $1 \mathrm{~h}$ at $37^{\circ} \mathrm{C}$. The lower chamber was filled with $750 \mu \mathrm{L}$ of DMEM at 10 $\%$ FBS and $1 \times 10^{5}$ of cells were seeded in the upper chambers $(250 \mu \mathrm{L}$ of DMEM at $1 \%$ FBS). Except for the control, all the cells were treated with different concentrations of the plant extract $(15,30,40,50$ and $60 \mu \mathrm{g} / \mathrm{mL})$ chosen below its $24 \mathrm{~h} \mathrm{IC}_{50}$ value. The cells were allowed to invade for $24 \mathrm{~h}$, after they were washed with PBS twice, fixed with $4 \%$ formaldehyde for $15 \mathrm{~min}$. Following this, formaldehyde was removed, cells were washed twice with PBS and permeabilized at RT for 20 min using $100 \%$ methanol. After permeabilization, the cells were again washed twice with PBS and stained with $0.2 \%$ crystal violet, incubated for $15 \mathrm{~min}$ at RT and washed with PBS. The non-invasive cells were removed from the top aspect of the membrane using cotton buds. For their quantification, cells were imaged under a Nikon Inverted Microscope ECLIPSE TE2000-S and counted using ImageJ software. All assays were performed at least three times. 


\subsection{Western blot analysis}

CaSki cells were seeded in 6-well plates at $3 \times 10^{5}$ cells per well followed by overnight incubation. After $24 \mathrm{~h}$ of treatment with concentrations of the plant extract, cells were washed with PBS, trypsinized and incubated with lysis buffer for $20 \mathrm{~min}$ at $-80{ }^{\circ} \mathrm{C}$. The lysate was then centrifuged at $14,000 \mathrm{rpm}$ for $20 \mathrm{~min}$ at $4{ }^{\circ} \mathrm{C}$. Protein quantification was performed using the Bradford protein assay kit. Protein lysates were boiled at $95{ }^{\circ} \mathrm{C}$ for $10 \mathrm{~min}$ along with Laemeli sample buffer. Proteins $(20 \mu \mathrm{g})$ were separated by $10 \%$ SDS-PAGE followed by electro-transfer onto polyvinylidene fluoride (PVDF) membranes. After blocking with 5\% non-fat dry milk in Tris buffered saline, containing $0.1 \%$ Tween 20 (TBST) at $37{ }^{\circ} \mathrm{C}$ for $1 \mathrm{~h}$, the membranes were incubated in TBST buffer with the primary antibodies. The primary antibodies used for in vitro assays were anti-E-cadherin (Cell Signaling Technology USA, 3195), anti-Snail (Cell Signaling Technology USA, 3879), anti-vimentin (Cell Signaling Technology USA, 5741), anti- $\beta$ catenin (Santa Cruz USA, 8480), anti-Slug (Cell Signaling Technology USA, 9585), anti-AKT(Cell Signaling Technology USA, 4691), anti-pAKT (Ser380) (Cell Signaling Technology USA, 4060), anti-pAKT (Thr 308) (Cell Signaling Technology USA, 13038) and pPTEN (Cell Signaling Technology USA, 9551). The primary antibodies used for the in vivo assay were anti-MMP2 (Cell Signaling Technology USA,87809), anti-MMP9 (Cell Signaling Technology USA,13667), anti-MT1-MMP (Cell Signaling Technology USA, 13130) and anti-GAPDH (Santa Cruz USA, SC-47724) at appropriate dilutions as recommended by the manufacturer. GAPDH was used as a loading control. After overnight incubation at $4{ }^{\circ} \mathrm{C}$, the blots were washed in Tris buffered saline containing $0.1 \%$ Tween 20 three times for $15 \mathrm{~min}$ each. Afterward, the blots were then incubated with anti-rabbit HRP secondary conjugated antibody (Santa Cruz USA, 7074) for $1 \mathrm{~h}$ at room temperature. Following this, all membranes were washed and developed with an 
ELC chemiluminescence kit. ImageJ software was used to estimate the band intensities on scanned images.

\subsection{Quantitative reverse transcription $P C R(R T-q P C R)$}

In order to investigate the expression of certain matrix metalloproteinase (MMP) genes involved in CaSki cell metastasis, the quantitative reverse transcription was performed on synthesised cDNAs. Total RNA was extracted from CaSki cells that were treated ( $24 \mathrm{~h})$ with methanolic root extract of I. cylindrica $(30,40,50$, and $60 \mu \mathrm{g} / \mathrm{mL})$ or vehicule $(0.1 \% \mathrm{DMSO})$ using Trizol reagent according to the manufacturer's protocol. RNA samples were resuspended in $20 \mu \mathrm{l}$ DEPC treated water, properly dissolved by incubating at $55{ }^{\circ} \mathrm{C}$ for 10 min and quantified using a Nano-Drop spectrophotometer (ThermoFischer Scientific). The First strand cDNA synthesis was done using SuperScript III cDNA synthesis kit from $2 \mu \mathrm{g}$ of the purified RNA. The cDNA obtained was used to perform real-time PCR using the QuantStudio Flex 6 RT-PCR machine (Applied biosystem, Foster City, USA) with respect to SYBR Green (Invitrogen) method. The RT-PCR was carried out using appropriate specific gene's primers obtained from Sigma-Aldrich, USA. MMP2 Forward 5'TGGCAAGTACGGCTTCTGTC-3', MMP2 Reverse 5'-TTCTTGTCGCGGTCGTAGTC-3', MMP7 Forward 5'-TGTTAAACTCCCGCGTCATA-3', MMP7 Reverse 5'GCGTTCATCCTCATCGAAGT-3', MMP9 Forward 5'-AGTCCACCCTTGTGCTCTTC3', MMP9 Reverse 5'- GCCACCCGAGTGTAACCAT-3', MT1-MMP Forward 5' AACCAGAAGCTGAAGGTAGAA-3', MT1-MMP Reverse CCAGAAGCUGAAGGUAGAA-3', GAPDH Forward 5'-GAGTCCACTGGCGTCTTC-3'

GAPDH Reverse 5'-GGGGTGCTAAGCAGTTGGT-3'. Gene expression levels were determined using the cycle threshold $(\mathrm{Ct})$ method. The mean $\mathrm{Ct}$ values from triplicate measurements were used to calculate the expression of the target gene with normalisation to a 
housekeeping gene (GAPDH) and the difference in fold expression was calculated using the $2^{-\Delta \Delta \mathrm{Ct}}$ method.

\subsection{CaSki Xenograft model}

The metastatic human cervical cancer cell line CaSki was cultured to subconfluently in Dulbeco's modified Eagle medium supplemented with $10 \%$ foetal bovin serum and $1 \%$ penicillin and streptomycin $(10 \mathrm{~mL} / \mathrm{L})$. Viable cells resuspended in fresh PBS and Matrigel to a concentration of $2 \times 10^{6}$ cells/ $200 \mu \mathrm{L}$, were injected subcutaneously into the right dorsal flanks of mice, and the tumor growth was monitored weekly. Five weeks after the tumor cell inoculation, mice were randomly divided in to six groups $(n=5)$ and were given intraperitoneal (IP) injections treatments daily for 15 days : the negative control group was given vehicle (5\% DMSO in $\mathrm{ddH}_{2} 0$ ), the positive control group was injected with cisplatin $\left(2 \mathrm{mg} \cdot \mathrm{Kg}^{-1}\right)$, while the remaining four groups of animals were treated with $I$. cylindrica root extract at doses of 50,100, 200 and $400 \mathrm{mg} \cdot \mathrm{Kg}^{-1}$. The plant extract treatment doses were chosen based on the acute and sub-chronic toxicity assay previously conducted on $I$. cylindrica root extract which showed that the latter is safe for long-term administration at 500

mg. $\mathrm{Kg}^{-1}$ body weight (bw) (Nayim et al., 2020). Tumor volumes were measured with a digital calliper and calculated using the formula: 1/2 (Length $\times$ Width $^{2}$ ), where width represents the shortest dimension of the tumor. At the end of the treatment period, all animals were sacrificed, tumors were surgically excised, their final volumes were measured, and they were snap frozen in liquid nitrogen and stored in $-80{ }^{\circ} \mathrm{C}$. Later, lysates were prepared from frozen tissue and western blot analysis was conducted on the samples from the control group and groups treated with effective doses of I. cylindrica root extract.

\subsection{RNA sequencing}


CaSki cells $\left(1.5 \times 10^{5}\right.$ cells $)$ were exposed to a concentration of $I$. cylindrica root extract chosen below its $\mathrm{IC}_{50}$ value i.e. $50 \mu \mathrm{g} / \mathrm{mL}$ for $24 \mathrm{~h}$ at $37^{\circ} \mathrm{C}$. Total RNA was extracted from treated and untreated cells using TRIzol reagent by following the manufacturer's instructions. RNA-Seq analyses were performed using Illumina HiSeq. Approximately 45-50 million reads (50bp, single end) per sample were generated at the Next Generation Genomics Facility of NCBS-TIFR. Reads were aligned to the human genome (GRCh38), version 35 (Ensembl 101) using STAR version 2.6.0a (Dobin et al., 2016). The alignment rate for all the samples was more than $80 \%$ ( $83.32-84.64 \%)$; in other words, more than $80 \%$ of the reads from each sample were uniquely aligned to the human genome. These mapped reads were counted for each annotated gene using featureCounts (v1.4.6-p5) (Liao et al., 2014). The read counts were normalised with the respected to library size and differentially expressed genes (DEGs) between the conditions were identified using DESeq2 (Love et al., 2014) with an alpha of 0.05 as the cut-off for significance (Wald test).

\subsection{Data analysis}

All the in vitro experiments were performed three times, on independent cell passages. In the cell proliferation assay, $\mathrm{IC}_{50}$ values were calculated from the concentration-inhibition curve by nonlinear regression analysis. Migration, invasion, RTqPCR and western blot data were plotted as mean \pm SD. Statistical analysis was done using GraphPad Prism Version 8.1.0 (GraphPad Software, CA, USA). Differences between the means of treated and untreated cells or groups were evaluated using one-way analysis of variance (one-way ANOVA) followed by post hoc Dunnett's multiple comparison test. P-values $<$ of 0.05 were considered to be statistically significant and significant, marked as * p-values $<0.05$, ** p-values $<0.01$, $* * * p$-values $<0.001$ and $* * * * p p<0.0001$. 


\section{Results}

\subsection{Cytotoxic potential of I. cylindrica root extract on human cervical cancer cell lines}

The roots of $I$. cylindrica contain various groups of phytochemicals known for their pharmacological activities. The cytotoxicity of $I$. cylindrica root methanol extract was assessed in vitro against a panel of three human cervical cell lines, SiHa, CaSki and HCK1T. The same plant extract was assessed for its in vivo antitumor activity. From the results depicted in Fig. 1a and Table 1, I. cylindrica root extract has inhibited the aforementioned cancer cells proliferation with $\mathrm{IC}_{50}$ values $(\mu \mathrm{g} / \mathrm{mL})$ of $103.8 \pm 1.29,80.49 \pm 2.2$ and $64.89 \pm 0.77$ for $\mathrm{SiHa} ; 65.14 \pm 3.350,55.52 \pm 0.816$ and $50.51 \pm 1.53$ for CaSki, respectively after 24,48 and $72 \mathrm{~h}$ of incubation. With respect to these incubation periods, cisplatin also impaired SiHa and CaSki cell proliferation as well. In general, I. cylindrica root extract as well as cisplatin displayed a concentration and time- dependent cytotoxicity effect against CaSki cells. In the normal cervical cell line HCK1T, both I. cylindrica root extract and cisplatin displayed a concentration and time-dependent cytotoxicity, as their $\mathrm{IC}_{50}$ values on this cell line were decreasing when the incubation periods where increasing. Mice bearing CaSki tumors were treated daily with $I$. cylindrica root extract and cisplatin for 15 days. As shown in Fig. 1 b, $I$. cylindrica root extract has significantly reduced $50 \%$ and $70 \%$ of the tumor volume respectively at $100 \mathrm{mg} \cdot \mathrm{Kg}^{-1} \mathrm{bw}(p<0.01)$, and at $200 \mathrm{mg} \cdot \mathrm{Kg}^{-1}(p<0.001)$ and $400 \mathrm{mg} \cdot \mathrm{Kg}^{-1}$ bw $(p<0.001)$; no significant reduction was obtained at $50 \mathrm{mg} \cdot \mathrm{Kg}^{-1}$. Cisplatin $(p<0.005)$ has also reduced more than $50 \%$ of the tumor volume. Supporting information (S1) shows the tumour pictures of untreated and treated animals.

\subsection{I. cylindrica root extract inhibits CaSki cell migration and invasion.}

Numerous studies have confirmed the existence of two main patterns of cancer cell invasion: collective cell migration and individual cell migration, by which tumor cells overcome 
barriers of the extracellular matrix and spread into surrounding tissues (Krakhmal et al., 2015). To determine the inhibitory effect of I. cylindrica root extract on CaSki cell migration, we performed a wound healing assay and a transwell migration assay. We found that CaSki cell migration was significantly inhibited when treated at $30,40,50$ and $60 \mu \mathrm{g} / \mathrm{mL}$ of plant extract compared to the untreated cells (control). Additionally, the anti-migrative potential of I. cylindrica root extract was concentration dependent as shown in Fig. 2a, 2b, 2c and 2d. To assess whether I. cylindrica root extract impairs CaSki cell invasion, we performed a Matrigel invasion assay. As shown in Fig. $2 \mathrm{e}$ and $2 \mathrm{f}$, one can noticed that $I$. cylindrica root extract significantly decreased CaSki cells invasion at 30,40, 50 and $60 \mu \mathrm{g} / \mathrm{mL}$ in concentration dependent manner, with respect to the control (untreated cells).

\subsection{I. cylindrica root extract inhibits the PI3K/Akt pathway and prevents epithelial-} mesenchymal transition.

For molecular changes in protein expression related to migration and invasion, and that mediated by I. cylindrica root extract, the expression of E-cadherin, $\beta$-catenin, vimentin, Snail and slug was investigated by western blotting (Fig. 3a and 3b). We have also assessed some proteins expression level involved in the phosphatidylinositol 3-kinase/AKT signaling pathway such as phospho-PTEN (Ser380), phospho-AKT (Ser473) and phosphor-AKT (Thr308) (Fig. 3c and 3d). Phosphorylation of the phosphatase and tensin homologue (PTEN) on Ser380 significantly increased in all the samples treated with $I$. cylindrica root extract at 30, 40, 50 and $60 \mu \mathrm{g} / \mathrm{mL}$, while the phosphorylation of AKT on Thr308 significantly decreased but not on the Ser473. No significant variation in total expression of AKT was observed in the treated samples with respect to the control (untreated sample). The AKT pathway is widely accepted as an enhancer of several cancer behaviors, including metastasis (Karlsson et al., 2017). The epithelial to mesenchymal phenotype is an essential process to 
achieve metastasis, one of the common cancer hallmark. The protein expression level of Ecadherin, a specific epithelial cell-cell adhesion molecule, was significantly upregulated in CaSki cells after $24 \mathrm{~h}$ treatment with I. cylindrica root extract. The protein levels of mesenchymal markers, such as vimentin and Snail were notably downregulated in a dosedependent manner. In addition, the same observation was made with $\beta$-catenin, which plays a key role during EMT process. However, no significant change in slug expression was observed in the treated samples compare to the control.

Matrix metalloproteinases (MMPs) are a family of structural and functional related endopeptidases involved in malignant cell invasion through the breakage of the extracellular matrix's components. Some of them are strongly involved in human cervical cancer cell CaSki metastasis (Kaewprag et al., 2013; Tanaka et al., 2019). Real-time PCR was conducted to assess the expression levels of MMP-2, MMP-7, MMP-9 and MT1-MMP in CaSki cells after $24 \mathrm{~h}$ treatment with $I$. cylindrica. At all the tested concentrations, a significant decrease in MMP-7 and MT1-MMP genes was observed in treated cells compared to untreated with a maximum of approximately tenfold decreases at $60 \mu \mathrm{g} / \mathrm{mL}(p<0.001)$. Compared to the control, the expression of MMP-2 and MMP-9 genes decreased significantly at 50 and 60 $\mu \mathrm{g} / \mathrm{mL}(p<0.05)$, while no significant changes were observed in the expression levels of these same genes at 30 and $40 \mu \mathrm{g} / \mathrm{mL}(p<0.05)$ (Fig. 3e).

\subsection{In vivo effect of I. cylindrica root extract on E-cadherin and matrix metalloproteinases} (MMPs) proteins expression

Western blotting was used to assess in vivo, the expression levels of MMP-2, MT1-MMP, MMP-9, as well as E-cadherin in CaSki tumors treated with different doses of I. cylindrica root extract. As shown in Fig. 4, the protein expression levels of E-cadherin were significantly upregulated at doses of 200 and $400 \mathrm{mg} \mathrm{Kg}^{-1}$ bw of I. cylindrica root extract. MT1-MMP and MMP-9 protein expression levels were significantly downregulated after $I$. 
cylindrica root extract treatment at 100,200 and $400 \mathrm{mg} . \mathrm{Kg}^{-1} \mathrm{bw}$, while no change was observed in MMP-2 expression compared to the control.

\subsection{Transcriptome response of CaSki cells treaded with I. cylindrica root extract.}

Gene expression profiling using RNA-Seq was carried out to determine the differentially regulated genes after treatment with I. cylindrica root extract. CaSki cells were treated with $50 \mu \mathrm{g} / \mathrm{mL}$ of the plant extract for $24 \mathrm{~h}$. Total RNA was extracted from control and $I$. cylindrica extract- treated CaSki, and RNA-Seq was carried out using Illumina HiSeq. Differentially expressed genes (DEGs) between the conditions were identified using DESeq2 (Love et al., 2014). Sequencing revealed a total of 120 genes whose expression was significantly altered $(\mathrm{P}<0.05)$ following treatment with I. cylindrica root extract $(50 \mu \mathrm{g} / \mathrm{mL})$ compared to CaSki cells treated with the vehicle (DMSO). This gene set comprised 62 genes $(\mathrm{P}<0.05)$ that were upregulated and 58 genes $(\mathrm{P}<0.05)$ that were downregulated. These are presented in Tables 2 and 3 and plotted in a volcano plot (Fig. 5). Various genes involved in cancer were differentially regulated after exposure of CaSki cells to I. cylindrica root extract. One of the important genes involved in cancer progression and metastasis of cervical cancer, that is, FN1 (fibronectin1) and CD24 (Cluster of Differentiation 24) were downregulated in CaSki cells after treatment with I. cylindrica root extract. Moreover, the tissue matrixmetalloproteinase Inhibitor-4 (TIMP-4) genes were upregulated. However, we observed a strong upregulation of AKR1C1 and HMOX1 genes, and a strong downregulation of IL24 and IGFBP5 in CaSki cells treated with I cylindrica root extract.

\section{Discussion}

Natural products have been used as a source for drug discovery against several diseases, including cancer. Various crude plant extracts and compounds from various plants have been reported for their anti-cancer properties through the disturbance of certain cell signalling 
pathways (Kuete et al., 2013; Majumder et al., 2019; Mbaveng et al., 2019; Buranrat et al., 2020) . The present study was designed to assess the in vitro and in vivo cytotoxic potential of I. cylindrica root extract, and its anti-metastatic effects in vitro against human cervical cancer. To assess the effect of I. cylindrica root extract on human cervical primary cancer, we have performed a cytotoxicity assay; furthermore, we conducted an in vivo antitumor assay to exhibit the tumor growth-arrest capacity of the plant extract. The results obtained show that $I$. cylindrica root extract has displayed a concentration and time-dependent anti-cancer effect against CaSki and SiHa cells after 24, 48 and 72h of treatment at different concentrations of the plant extract. Moreover, in our in vivo study, I. cylindrica root extract showed a significant and dose-dependent reduction of about $50 \%\left(100 \mathrm{mg} . \mathrm{Kg}^{-1}\right.$ b.w) to $70 \%$ (200 mg. $\mathrm{Kg}^{-1}$ and $400 \mathrm{mg} \cdot \mathrm{Kg}^{-1}$ b.w ) of the CaSki tumor sizes compared to the untreated groups of mice. These outcomes correlate with previous investigations carried out on this plant species, which have revealed its cytotoxicity against other types of cancer including breast cancer, blood cancer and human liver hepato-cellular carcinoma (Kuete et al., 2013; Ravi et al., 2017). Several other studies have already described the anti-tumour activity of natural products, especially plant extracts, against several types of cancers (Majumder et al., 2019; Longato et al., 2019; Akindele et al., 2015), but to the best of our knowledge, there is no literature reporting the antitumor effects of the methanolic root extract of $I$. cylindrica root extract against the human cervical cancer cell line CaSki.

To investigate the anti-metastatic potential of I. cylindrica root extract against the human cervical cancer cell line CaSki, derived from an epidermoid carcinoma of the cervix metastatic to the small bowel mesentery, we set in vitro assays with concentrations chosen below the $\mathrm{IC}_{50}$ value of the plant extract against this cell line or the doses that significantly reduced the tumour volume in vivo. Metastasis is a multistep process including migration and invasion of cancer cells, hallmarks of malignancy (Lubna et al., 2019). In our study, genome- 
wide transcriptome analysis indicated that I. cylindrica root extract significantly affected genes related to cell migration, cell invasion, and cell motility pathways which are closely related to cell metastasis. Furthermore, we demonstrated that $I$. cylindrica root extract has an inhibitory effect on cell migration, invasion and colony formation based on cellular phenotypic experiments.

Transcriptome analysis revealed a significant downregulation of the Cluster of Differentiation 24 (CD24)'s gene expression in CaSki cell, a gene well known to promote metastasis in the human cervical cancer cell line CaSki and many other cancer cell migration and invasion, through activation of cell signalling proteins, including Akt, ERK and NF- $\mathrm{B}$, and increased expression of epithelial marker E-cadherin and decreased of mesenchymal markers (Ahmed and Ilyas, 2014; Tanaka et al., 2015). Moreover, CD24 induces EMT via the activation of PI3K/Akt, NF- $\mathrm{BB}$ and ERK in cancer cells (Nakamura et al., 2017). In our study, I. cylindrica root extract significantly upregulated the protein expression level of Ecadherin in vitro and in vivo, and repressed those of Snail, $\beta$-catenin and vimentin. The plant extract also affected the PI3K/AKT pathway via the downregulation of p-AKT (Thr308) and the upregulation of p-PTEN (Ser380), which negatively regulates the PI3K/AKT pathway by dephosphorylating PIP3 to PIP2, thus preventing the activation of downstream kinases (Chagpar et al., 2010). Abnormalities of the PI3K/AKT pathway in different cancers are closely related to EMT and metastasis of cancer cells (Jiang et al., 2020). The activation of

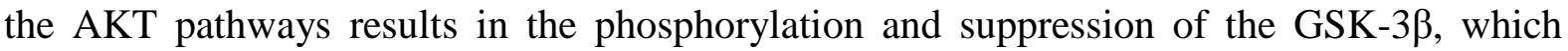
regulates the stability of $\beta$-catenin ( $\mathrm{Li}$ and Zhou, 2011) and Snaill, which repressed Ecadherin and induced vimentin. EMT is a biological process that allows polarised epithelial cells, which normally interact with the basement membrane via its basal surface, to loss their cell polarity and cell-cell adhesion and gain migratory and invasive properties to become mesenchymal stem cells and greatly increase the production of ECM components (Kalluri 
and Neilson, 2003). EMT plays a critical role in abnormal pathological events such as tumor transformation and metastasis (Aeshra et al., 2020).

Tissue inhibitors of matrix metalloproteinase (TIMPs) are specific inhibitors that bind to the zinc at the active centre of the MMPs in a 1:1 stoichiometry, thereby blocking their activity directly (Frederick, 1999; Brew et al., 2000; Benjamin and Khalil, 2012). As shown by the transcriptomic profile of our study, TIMP-4 gene expression in I. cylindrica-treated cells was significantly upregulated. According to Zavadzkas et al. (2014), TIMP-4 induction reduces MMP-2 and MMP-9 levels. In the current study, we have validated the TIM-4 gene's targets that are closely related to cervical cancer metastasis at the protein and /or mRNA levels. I. cylindrica's root extract significantly altered, in a concentration-dependent manner, expression of MMP-2, MMP-7, MMP-9 and MT1-MMP at the mRNA levels in CaSki cells after $24 \mathrm{~h}$ in vitro's treatment. Moreover, the protein's levels of MMP-9 and MT1-MMP were significantly downregulated in vivo in a dose-dependent manner after 15 days of treatment. MMPs are a family of structural and functional related endopeptidases enzymes playing a critical role during the human cervical cancer cell CaSki metastasis process as verified by Tanaka et al. (2019) for the case of MMP-9, while Kaewprag et al. (2013) demonstrated that HPV16E6 and E7 oncoproteins cooperate in promoting CaSki, SiHa and HeLa invasiveness by specifically upregulating MMP-2 and MT1-MMP transcription. Moreover, from the findings of Zhu et al. (2018), MMP-7 expression was significantly higher in the tissue and serum of cervical cancer patients than in healthy individuals, and this was correlated with increased pathological grade, clinical stage, and lymph metastasis. All these findings suggested that overexpression of MMP-2, MMP-7, MMP-9 and MT1-MMP in human cervical cancer is correlated with their metastasis properties, and I. cylindrica root extract induces the downregulation of these MMPs through the upregulation of TIMP-4. 


\section{Conclusion}

Our study provide the anticancer activity and mechanism of action of I.cylindrica root extract against the human cervical cancer cell line CaSki. I. cylindrica root metabolites are cytotoxic to human cervical cancer, they prevent invasion and metastasis of this specific cancer by inhibiting the PI3/AKT pathway and EMT process via the downregulation of clinically highrisk metastasis-promoting gene $\mathrm{CD} 24$, and the upregulation of the TIMP-4 gene.

\section{Acknowledgements}

The World Academy of Science (TWAS) and Department of Biotechnology (DBT) of India for the award of DBT-TWAS fellowship.

The animal work in the NCBS/inStem Animal Care and Resource Centre, partially supported by the National Mouse Research Resource (NaMoR) grant\# BT/PR5981/MED/31/2012;2013-2016 \& 102/IFD/SAN5003/2017-2018 from the Indian Department of Biotechnology.

Swati Choudhary, Shefta E moula and Bhagyashree S. for their assistance in some experiments.

\section{Author contributions}

V.K., S.K., S.M., and M.T.A., designed the study. N.P. performed the experimental work and wrote the manuscript. R.J. performed the RNAseq data analysis. All authors have reviewed the manuscript.

\section{Declaration of Competing Interest}

The authors declare no conflict of interest.

\section{References}


Aeshra, L.A., Moustafa, M., Elmallah, M.I.Y., Salih, S.A., Kader, I.Y.A., 2020. Correction to:

The role of epithelial-mesenchymal transition (EMT)-associated genes during gonadogenesis of albino rat. JoBAZ. 81, 2.

Ahmed, M.A.H., Ilyas, M., 2014. CD24 expression is associated with epithelial mesenchymal transition (EMT) phenotype and alterations in actin cytoskeleton in colorectal cancer. Pathology. 2014; 46: S105.

Akindele, A.J., Wani, Z.A., Sharma, S., Mahajan, G., Satti, N.K., Adeyemi, O.O., Mondhe, D.M., Saxena, A.K., 2015. In Vitro and In Vivo Anticancer Activity of Root Extracts of Sansevieria liberica Gerome and Labroy (Agavaceae). Evid.-Based Complementary Altern. Med. 2015; https://doi.org/10.1155/2015/560404.

Benjamin, M.M., Khalil, R.A., 2012. Matrix Metalloproteinase Inhibitors as Investigative Tools in the Pathogenesis and Management of Vascular Disease. Experientia Suppl. 103, 209-279.

Bray, F., Ferlay, J., Soerjomataram, I., Siegel, R. L., Torre, L. A., Jemal, A., 2018. A Cancer Journal for Clinicians Global Cancer Statistics 2018: GLOBOCAN Estimates of Incidence and Mortality Worldwide for 36 Cancers in 185 Countries. CA: Cancer J. Clin. 68, 394-424.

Brew, K., Dinakarpandian, D., Nagase, H., 2000. Tissue inhibitors of metalloproteinases: evolution, structure and function. Biochim. Biophys. Acta. 1477, 267-283.

Buranrat, B., Noiwetch, S., Suksar, T., Ta-ut, A., 2020. Inhibition of cell proliferation and migration by Oroxylum indicum extracts on breast cancer cells via Rac1 modulation. J. Pharm. Anal. 10, 187-193 .

Chagpar, R.B., Links, P.H., Pastor, M.C., Furbera, L.A., Hawryshb, A.D., Chamberlaina, M.D., Andersonb, D.H., 2010. Direct positive regulation of PTEN by the p85 subunit of phosphatidylinositol 3-kinase. Proc. Natl Acad. Sci. 107, 5471-5476.

Crosbie, E., Einstein, M., Franceschi, S., Kitchener, H. C., 2013. Human papillomavirus and cervical cancer. Sem. 382, 889-899.

Dobin, A., Davis, C.A., Schlesinger, F., Drenkow, J., Zaleski, C., Jha, S., Batut, P., Chaisson, M., Gingeras, T.R.,2016. STAR: Ultrafast universal RNA-seq aligner. Bioinformatics. $29,15-21$.

Dzoyem, J.P., Tchuenguem, T.R., Kuiate, J-R., Teke, G.N., Kechia, F.A., Kuete, V., 2014. In Vitro and In Vivo antifungal activities of selected Cameroonian dietary spices. BMC Complem. and Altern. M. 14, 58. 
Frederick, W.,1999. Matrix Metalloproteinase Inhibition: From The Jurassic To The Third Millennium. Ann. N. Y. Acad. Sci. 878, 388-403.

Heerboth, S., Housman, G., Leary, M., Longacre, M., Byler, S., Lapinska, K., Willbanks, A., Sarkar, S., 2015. EMT and tomour metastasis. Clin. Transl. Med. 4, 6.

Hubbard, C.E., Whyte, R.O., Brown, D., Gray, A.P., 1944. Imperata cylindrica. Taxonomy, Distribution, Economic Significance, and Control. Commonwealth Agri. Bureau. 1944 ;

\section{7: 20057006078 .}

Jiang, N., Dai, Q., Su, X., Fu, J., Feng, X., Peng, J., 2020. Role of PI3K/AKT pathway in cancer: the framework of malignant behaviour. Mol. Biol. Rep. 47, 4587-4629.

Kaewprag, J., Umnajvijit, W., Ngamkham, J., Ponglikitmongkol, M., 2013. HPV16

Oncoproteins Promote Cervical Cancer Invasiveness by Upregulating Specific Matrix

Metalloproteinases. Plos one. 8, e71611.

Kalluri, R., Neilson, E.G., 2003. Epithelial-mesenchymal transition and its implications for fibrosis. J. Clin. Invest. 112, 1776-1784.

Karlsson, M.C., Gonzalez, S.F., Welin, J., Fuxe, J. Epithelial-mesenchymal transition in cancer

metastasis through the lymphatic system. Mol. Oncol. 2017; 11: 781-791.

Krakhmal, N.V., Zavyalova, M.V., Denisov, E.V., Vtorushin, S.V., Perelmuter, V.M., 2015. Cancer Invasion: Patterns and Mechanisms. Acta Naturae. 7,17-28.

Kuete, V., Djeussi, D.E., Mbaveng, A.T., Zeino, M., Efferth, T. 2016. Cytotoxicity of 15 Cameroonian medicinal plants against drug sensitive and multi-drug resistant cancer cells. J. Ethnopharmacol. 186, 196-204.

Kuete, V., Sandjo, L.P., Wiench, B., Efferth, T., 2013. Cytotoxicity and modes of action of four Cameroonian dietary spices ethno-medically used to treat Cancers: Echinops giganteus, Xylopia aethiopica, Imperata cylindrica and Piper capense. J. Ethnopharmacol. 149, 245-253.

Kwok, A.H., Wang, Y.Y., Wing, S.H., 2016. Cytotoxic and pro-oxidative effects of Imperata cylindrica aerial part ethyl acetate extract in colorectal cancer in vitro. Phytomedicine. $23,558-556$.

Li, H., Wu, X., Cheng, X., 2016. Advances in diagnosis and treatment of metastatic cervical cancer. J. Gynecol. Oncol. 27, e43.

Li, J., Zhou, B.P., 2011. Activation of beta-catenin and Akt pathways by Twist are critical for 
the maintenance of EMT associated cancer stem cell-like characters, BMC Cancer. $2011 ; 11,49$.

Liao, Y., Smyth, G.K., Shi, W., 2014. FeatureCounts: An efficient general purpose program for assigning sequence reads to genomic features. Bioinformatics. 30, 923-930.

Longato, G.B., Rizzo, L.Y., 2011. Maria de Oliveira Sousa I, Tinti SV, Possenti A, Figueira GM, Ruiz ALTG, Foglio MA, Ernesto de Carvalho J. In vitro and in vivo anticancer activity of extracts, fractions, and eupomatenoid-5 obtained from Piper regnellii leaves. Planta Med. 77, 1482-1488.

Love, M.I., Huber, W., Anders, S., 2014. Moderated estimation of fold change and dispersion for RNA-seq data with DESeq2. Genome Biol. 15, 550.

Lubna, T., Mamoun, Jennifer, K., Christian, R., 2019. Molecular Regulation of Cancer Cell Migration, Invasion, and Metastasis. Anal. Cell Pathol (Amst). 2019, 1356508.

Majumder, M., Debnath, S., Gajbhiye, R.L., Saikia, R., Gogoi, B., Samanta, S.K., Das, D.K., Biswas, K., Jaisankar, P., Mukhopadhyay, R., 2019. Ricinus communis L. fruit extract inhibits migration/invasion, induces apoptosis in breast cancer cells and arrests tumor progression in vivo. Sci. Rep. 9,14493.

Matsunaga, K., Ikeda, M., Shibuya, M., Ohizumi, Y., 1994a. Cylindol A, a novel biphenyl ether with 5-lipoxygenase inhibitory activity, and a related compound from Imperata cylindrica. J. Nat. Prod. 57,1290-1293.

Matsunaga, K., Shibuya, M., Ohizumi, Y., 1994b. Cylindrene, a novel sesquiterpenoid from Imperata cylindrica with inhibitory activity on contractions of vascular smooth muscle. J. Nat. Prod. 57,1183-1184.

Matsunaga, K., Shibuya, M., Ohizumi, Y., 1995. Imperanene, a novel phenolic compound with

platelet aggregation inhibitory activity from Imperata cylindrica. J. Nat. Prod. 58,138139.

Matsunaga, K., Shibuya, M., Ohizumi, Y.,1994c. Graminone B, a novel lignan with vasodilative activity from Imperata cylindrica. J. Nat. Prod. 57, 1734-1736.

Mbaveng, A.T., Bitchagno, G.T.M., Kuete, V., Tane, P., Efferth, T., 2019. Cytotoxicity of ungeremine towards multi-factorial drug resistant cancer cells and induction of apoptosis, ferroptosis, necroptosis and autophagy. Phytomedicine. 60, 28-32.

Nakamura, K., Terai, Y., Tanabe, A., Ono, Y.J., Hayashi, M., Maeda, K., Fujiwara, S., Ashihara, K., Nakamura M, Tanaka, Y., Tanaka, T., Tsunetoh, S., Sasaki, H., Ohmichi, M., 2017. CD24 expression is a marker for predicting clinical outcome and 
regulates the epithelial-mesenchymal transition in ovarian cancer via both the Akt and ERK pathways. Oncol. Rep. 37, 3189-3200.

Nayim, P., Mbaveng, A.T., Ntyam, A.M., Kuete, V., 2020. A botanical from the antiproliferative Cameroonian spice, Imperata cylindrica is safe at lower doses, as demonstrated by oral acute and sub-chronic toxicity screenings. BMC Complement. Med. Ther. 20, 273.

Newman DJ, Cragg GM. Natural Products As Sources of New Drugs over the 30 Years from 1981 to 2010. J. Nat. Prod. 2012;75:311-335.

Oyindamola, O., Abiodun, G.O., Gbotosho, G.O., Ajaiyeoba, E.O., Brun, R., Oduola, A.M., 2012. Antitrypanosomal activity of some medicinal plants from Nigerian ethnomedicine. Parasitol. Res.110, 521-526.

Park, J.H., 2004. Medicinal Plants of Korea. Shinil Publishing Co. 101.

Pranatharthi, A., Thomas, P., Udayashankar, A.V., Bhavani, C., Suresh, S.B., Sudhir, K., Thatte, J., Srikantia, N., Ross, C.R., Sweta, S.R., 2019. RhoC regulates radioresistance via crosstalk of ROCK2 with the DNA repair machinery in cervical cancer. J. Exp. Clin. Cancer Res.38, 392.

Qian, C.N., Mei, Y., Zhang, J., 2017. Cancer metastasis: issues and challenges. Chin. J. Cancer.

36,38 .

Ravi, S., Kaleena, P.K., Babu, M., Janaki, A., Velu, K., Elumalai., 2017. Phytochemical screening, antioxidant and anticancer potential of Imperata cylindrica (L.) raeusch against human breast cancer cell line (MCF-7). Int. J. Pharm. 8, 938-945.

Steeg, P. S., 2016. Targeting metastasis. Nat. Rev. Cancer. 16, 201-218.

Tanaka, T., Terai, Y., Kogata, Y., Ashihara, K., Maeda, K., Fujiwara, S., Yoo, S., Tanaka, Y., Tsunetoh, S., Sasaki, H., Kanemura, M., Tanabe, A., Ohmichi, M., 2015. CD24 expression as a marker for predicting clinical outcome and invasive activity in uterine cervical cancer. Oncol. Rep. 34, 2282-2288.

Tanaka, T., Terai, Y., Ohmichi, M., 2019. Association of matrix metalloproteinase-9 and decorin expression with the infiltration of cervical cancer. Oncol. Lett. 17, 1306-1312. Unnati, S., Ripal, S., Sanjeev, A., Niyati, A., 2013. Novel anticancer agents from plant sources.

Chin. J. Nat. Medicines.11,16-23.

Voukeng, K.I., Kuete, V., Dzoyem, J.P., Fankam, A.G., Noumedem, J.A.K., Kuiate, J-R., 
Pages, J-M., 2012. Antibacterial and antibiotic-potentiation activities of the methanol extract of some Cameroonian spices against Gram-negative multi-drug resistant phenotypes. BMC Res. Notes. 5, 299.

Zavadzkas, J.A., Stroud, R.E., Bouges, S., Mukherjee, R., Jones, J.R., Patel, R.K., McDermott,

P.J., Spinale, F.G., 2014. Targeted Overexpression of Tissue Inhibitor of Matrix Metalloproteinase-4 Modifies Post Myocardial Infarction Remodeling in Mice. Circ. Res. 114, 1435-1445.

Zhu, L., Zheng, X., Du, Y., Xing, Y., Xu, K., Cui, L., 2018. Matrix metalloproteinase-7 may serve as a novel biomarker for cervical cancer. Onco. Targets Ther. 11, 4207-4220.

\section{List of figures}

Fig. 1 In vitro and In vivo cytotoxicity of I. cylindrica root extract against cervical cancer cells.

Fig. 2 Anti-migrative and anti-invasive effect of $I$. cylindrica root extract..

Fig. 3 Effect of I. cylindrica root extract on EMT, MMPs and PI3K/AKT pathway.

Fig. 4 In vivo effect of I. cylindrica root extract on E-cadherin and MMPs

Fig. 5 Differential gene expression of I. cylindrica root extract treated-CaSki cells versus untreated CaSki cells. 


\section{Figure 1.}

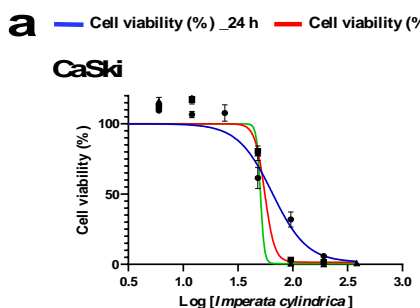

SiHa
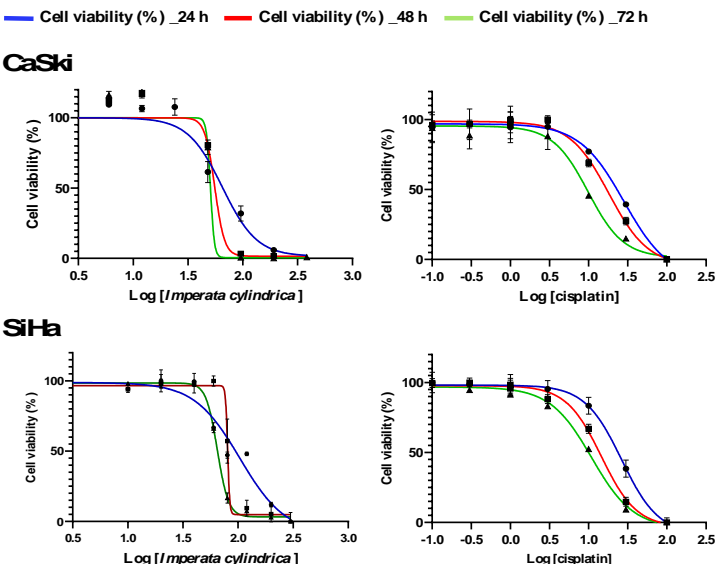

b

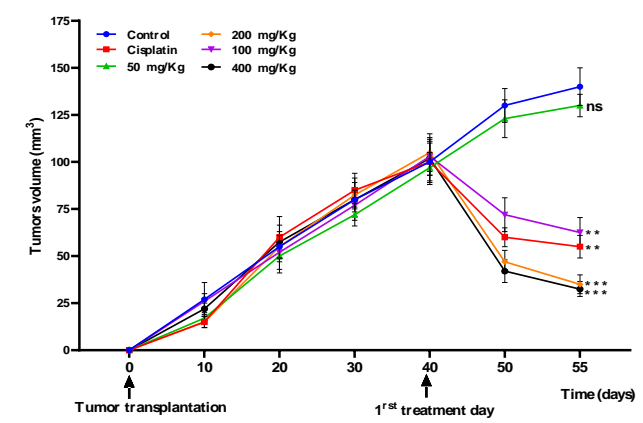

HCK1T
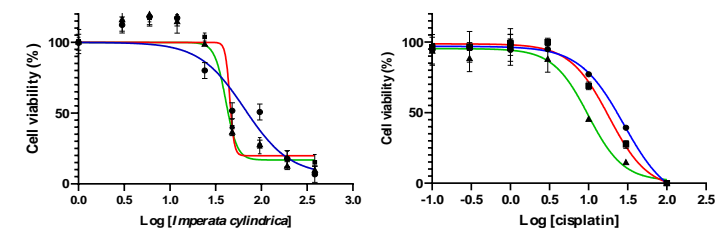

Fig. 1 In vitro and in vivo cytotoxicity of I. cylindrica root extract against cervical cancer cells. (a) Cytotoxicity of I. cylindrica root extract and cisplatin against cervical cancer cell lines CaSki, SiHa and normal cervix cell 
line HECK1T by WST colorimetric assay. Assays are representative of at least three independent experiments $(\mathrm{n}=3)$. (b) Evolution of the tumors growth before and during the treatment periods. The data were plotted as mean \pm SD. Differences between the means of treated and untreated cells were evaluated using one-way analysis of variance (one-way ANOVA) followed by post hoc Dunnett's multiple comparison test. p-values $<0.05$ were considered to be statistically significant and significance marked as $* p$-values $<0.05$ vs control, $* *$ $p$-values vs control $<0.01$, and $* * * p$-values vs control $<0.001$.

\section{Figure 2.}




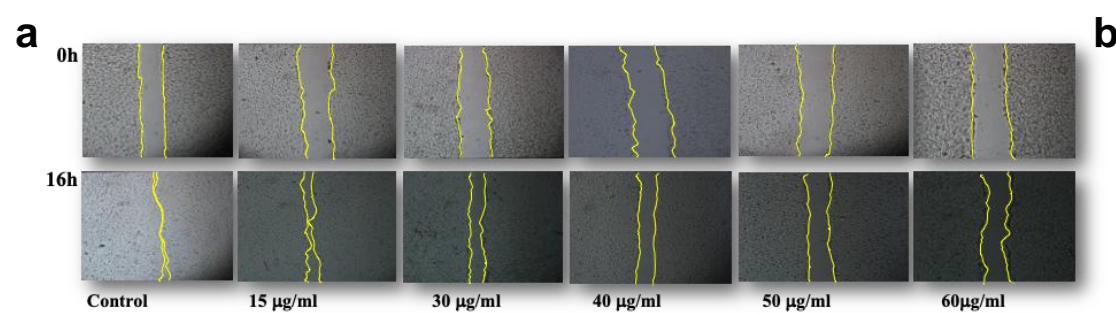

C

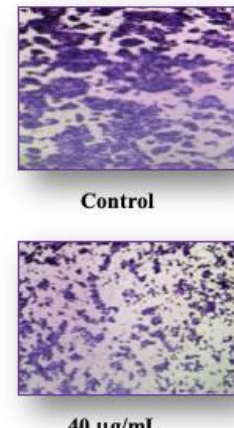

$40 \mu \mathrm{g} / \mathrm{mL}$

\section{e}
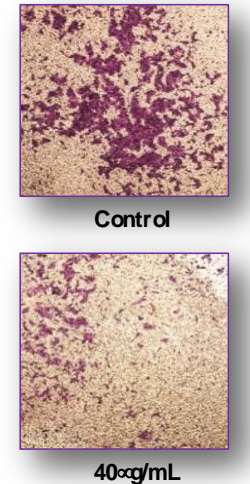

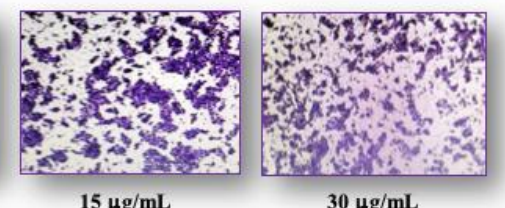

$15 \mu \mathrm{g} / \mathrm{mL}$

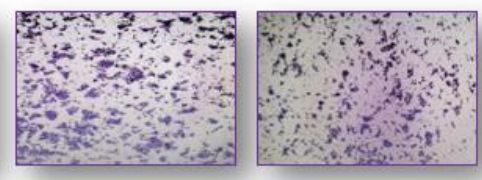

$50 \mu \mathrm{g} / \mathrm{mL}$

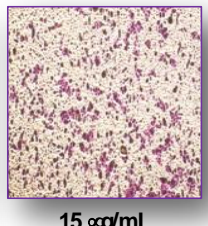

$15 \propto \mathrm{g} / \mathrm{mL}$

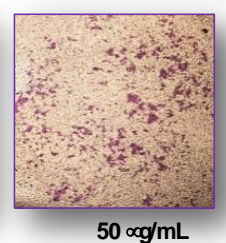

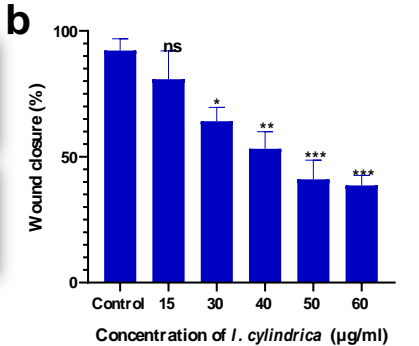

d

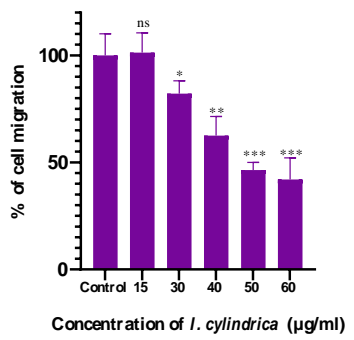

f

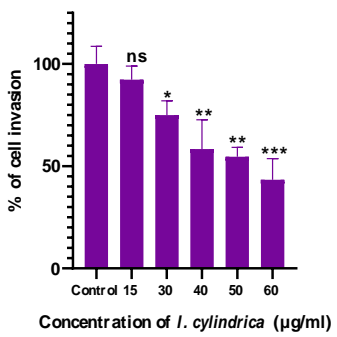

Fig. 2 Anti-migrative and anti-invasive effects of I. cylindrica root extract using CaSki cell line. (a) Artificial wounds in the treated and untreated cells before and after I. cylindrica root extract's treatment. (b) Percentage area of wounds closer in treated cells relative to untreated cells after I. cylindrica root extract's treatment. (c) Migrated cells in the treated and untreated group after $24 \mathrm{~h}$ of incubation. (d) Percentage of cell migration after $24 \mathrm{~h}$ of incubation. (e) Invaded cells in treated and untreated group after $24 \mathrm{~h}$ of incubation. (f) Percentage of cell invasion after $24 \mathrm{~h}$ of incubation. The data were plotted as mean $\pm \mathrm{SD}$. Differences between the means of treated and untreated cells were evaluated using one-way analysis of variance (one-way ANOVA) followed by post hoc Dunnett's multiple comparison test. p-values $<0.05$ were considered to be statistically significant and significance marked as $* p$-values $<0.05$ vs control, $* * p$-values vs control $<0.01$, and $* * * p$-values vs control $<0.001$. ns: non-significant.

\section{Figure 3.}



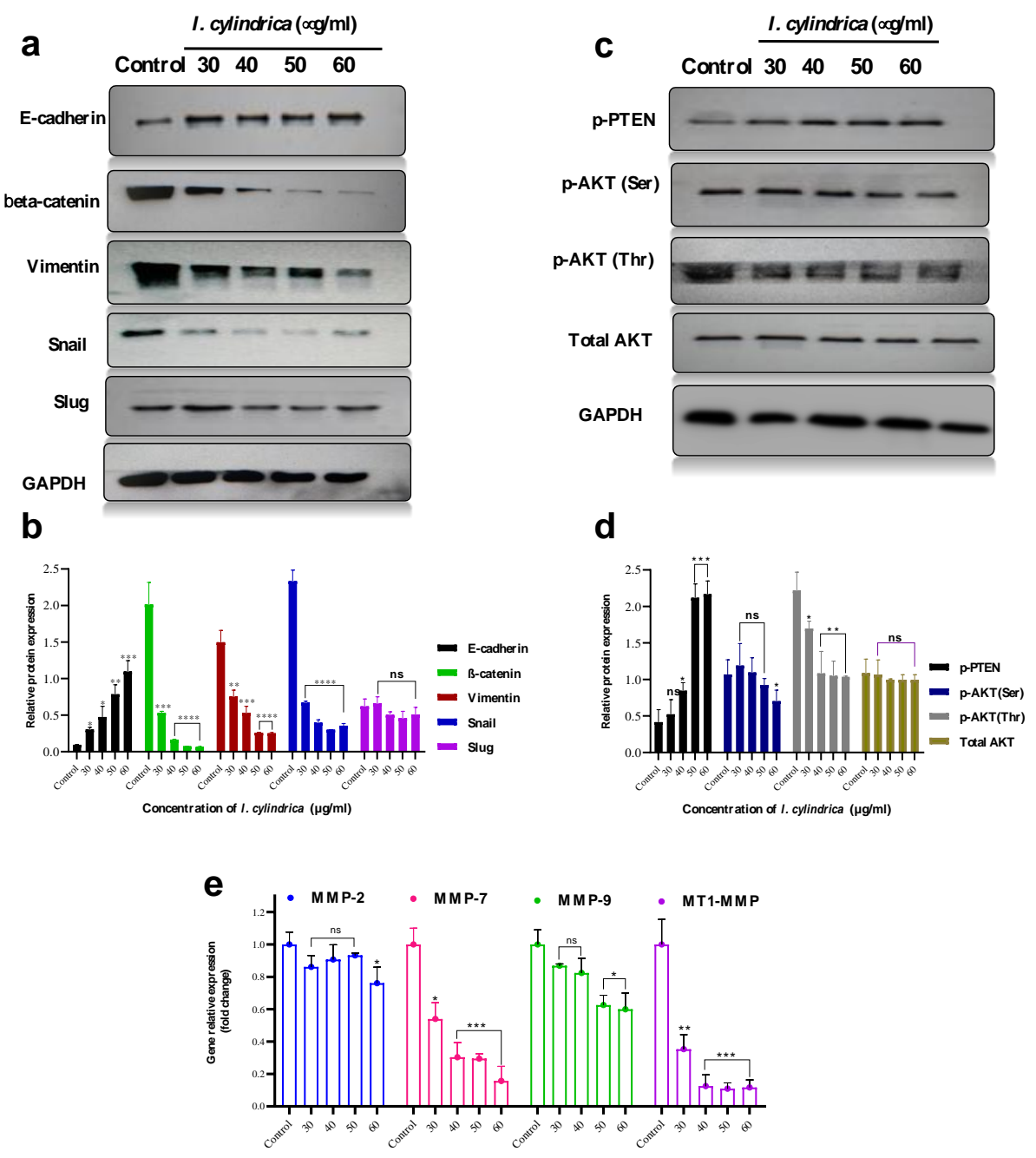

[I. cylindrica] $(\mu \mathrm{g} / \mathrm{ml})$

Fig. 3 Effect of I. cylindrica root extract on EMT, MMPs and PI3K/AKT pathway. (a) Expression levels of Ecadherin, beta-catenin, vimentin, Snail, and slug in CaSki cell treated with I. cylindrica root extract for $24 \mathrm{~h}$, were detected with western blotting. (b) The relative protein expression of E-cadherin, beta-catenin, vimentin, Snail, and slug of were quantified by normalizing to GAPDH. (c) Expression levels of p-PTEN (Ser380), pAKT (Ser473), p-AKT (Thr308) and total AKT in CaSki cells treated with I. cylindrica root extract, for 24 hours were detected with western blotting. (d) Relative protein expression of p-PTEN (Ser380), p-AKT (Ser473), p-AKT (Thr308) and total AKT quantified by normalizing to GAPDH. (e) Gene expression levels of matrix metalloproteinases, MMP-2, MMP-7, MM-9 and MT1-MMP in CaSki cell treated with I. cylindrica root extract. Gene expression levels of matrix metalloproteinases, MMP-2, MMP-7, MM-9 and MT1-MMP in CaSki cells treated with I. cylindrica root extract. Gene expression levels were quantified by real-time PCR. Data shown represent the mean fold change $( \pm \mathrm{SD})$ relative to GAPDH. $P$-values $<$ of 0.05 were considered to 
be statistically significant and significance marked as * p-values $<0.05$ vs control, $* * p$-values vs control $<0.01$, and $* * * p$ values vs control $<0.001$. ns: non-significant. 


\section{Figure 4.}
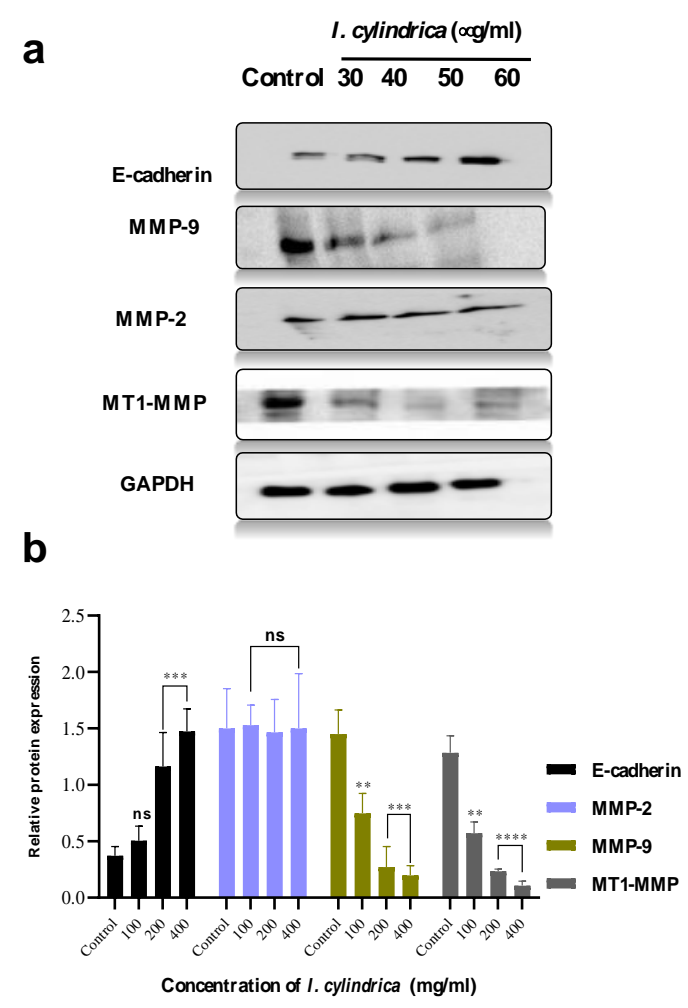

Fig. 4 In vivo effect of I. cylindrica root extract on E-cadherin and MMPs. (a) Expression levels of E-cadherin, Matrix metalloproteinase (MMP)-2, MMP-9, MT1-MMP in CaSki tumors treated with different doses of $I$. cylindrica root extract, for 15 days detected with western blotting. (b)The relative proteins of E-cadherin, Matrix metalloproteinase (MMP)-2, MMP-9, MT1-MMP expression. Relative protein expression was quantified by normalising to GAPDH used as an internal control. All data are presented as the mean \pm SD and are representative of three independent experiments. $p$-values $<0.05$ were considered to be statistically significant and significant marked as $* p$-values $<0.05$ vs control, $* *$-values vs control $<0.01, * * * p$-values vs control $<0.001$, and $* * * * p p<0.0001$ vs control. 
Figure 5.

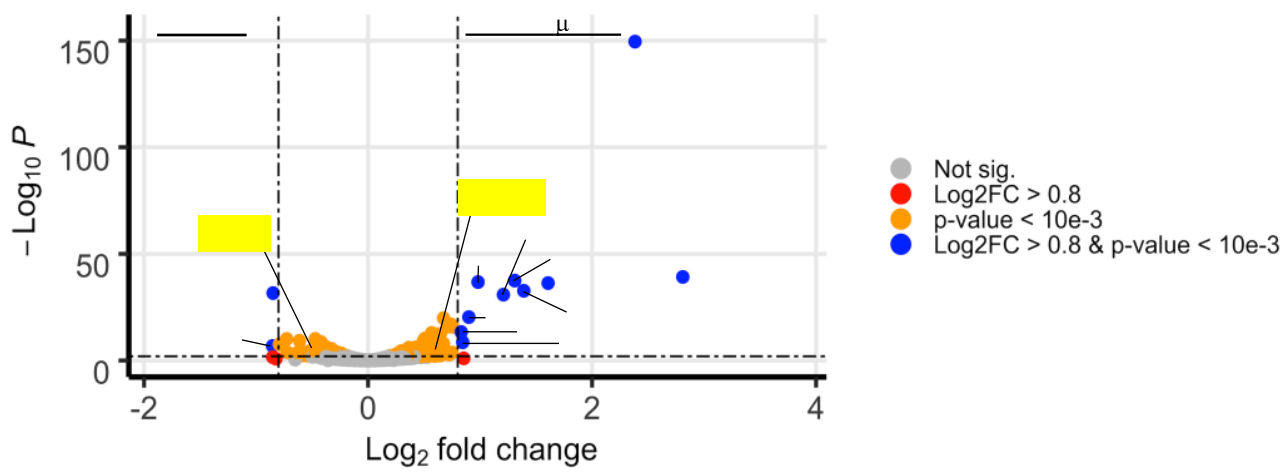

Fig. 5 Differential gene expression of I. cylindrica treated-CaSki cells versus untreated CaSki cells, with fold difference between $\log 2$ normalized expression in control $(n=2)$ and ICE treated $(n=2)$ plotted versus $-\log 10$ adjusted P-value. Each gene is coloured based on the $\log 10$ base mean expression. ICE: Imperata cylindrica root extract 


\section{List of tables.}

Table 1. Summary of the Inhibitory concentration $50(\mu \mathrm{g} / \mathrm{ml})$ of $I$. cylindrica root extract and cisplatin against cervical cell lines

Table 2. List of the significantly upregulated genes in CaSki after exposure to I. cylindrica root extract

Table 3. List of the significantly downregulated genes in CaSki after exposure to I. cylindrica root extract 
Table1. Summary of the Inhibitory concentration $50(\mu \mathrm{g} / \mathrm{ml})$ of $I$. cylindrica root extract and cisplatin against cervical cell lines

\begin{tabular}{|c|c|c|c|c|c|c|c|c|c|}
\hline \multirow{3}{*}{\begin{tabular}{|c|c|} 
Cell line \\
Treatment time
\end{tabular}} & \multicolumn{6}{|c|}{$\mathrm{IC}_{50}$ values in $\mu \mathrm{g} / \mathrm{ml}$ and selectivity index ${ }^{\mathrm{a}}$ (in bracket) } & \multirow{2}{*}{\multicolumn{3}{|c|}{ HCK1T }} \\
\hline & \multicolumn{3}{|c|}{ Caski } & \multicolumn{3}{|c|}{ SiHa } & & & \\
\hline & $24 \mathrm{~h}$ & $48 \mathrm{~h}$ & $72 \mathrm{~h}$ & $24 \mathrm{~h}$ & $48 \mathrm{~h}$ & $72 \mathrm{~h}$ & $24 \mathrm{~h}$ & $48 \mathrm{~h}$ & $72 \mathrm{~h}$ \\
\hline $\begin{array}{l}\text { I. cylindrica root } \\
\text { extract }\end{array}$ & $\begin{array}{l}65.14 \pm 3.35 \\
\quad(\mathbf{1 . 0 0 6})\end{array}$ & $\begin{array}{l}55.52 \pm 0.82 \\
\quad(\mathbf{0 . 8})\end{array}$ & $\begin{array}{c}50.71 \pm 1.53 \\
(\mathbf{0 . 8 0})\end{array}$ & $\begin{array}{c}103.8 \pm 1.29 \\
(\mathbf{0 . 6 3})\end{array}$ & $\begin{array}{c}80.49 \pm 2.2 \\
(\mathbf{0 . 5 6 )}\end{array}$ & $\begin{array}{c}64.89 \pm 0.77 \\
(\mathbf{0 . 6 3})\end{array}$ & $65.54 \pm 2.1$ & $45.19 \pm 1.7$ & $40.91 \pm 2$ \\
\hline Cisplatin & $\begin{array}{c}26.29 \pm 1.7 \\
(\mathbf{1 . 0 7})\end{array}$ & $\begin{array}{c}12.07 \pm 1.0 \\
(\mathbf{1 . 5})\end{array}$ & $\begin{array}{c}6.40 \pm 0.370 \\
(\mathbf{1 . 5 2})\end{array}$ & $\begin{array}{c}26.36 \pm 1.35 \\
(\mathbf{1 . 0 7 )}\end{array}$ & $\begin{array}{c}14.52 \pm 0.53 \\
\text { (1.25) }\end{array}$ & $\begin{array}{c}10.9 \pm 0.05 \\
(\mathbf{0 . 9 0 1 )}\end{array}$ & $28.23 \pm 1.41$ & $18.15 \pm 1.01$ & $9.83 \pm 0.7$ \\
\hline
\end{tabular}

\footnotetext{
${ }^{\mathbf{a}}$ The selectivity index was determined as the ratio $\mathrm{IC}_{50}$ value in the $\mathrm{HCK} 1 \mathrm{~T}$ normal cervical cell divided by the $\mathrm{IC}_{50}$ value in the cervical cancer line.
} 
Table 2. List of the significantly upregulated genes in CaSki after exposure to I. cylindrica root extract

\begin{tabular}{|c|c|c|c|c|c|c|c|}
\hline Gene IDs & Gene & $\begin{array}{c}\log 2 \\
\text { (Fold Change) }\end{array}$ & $p$-value & Gene IDs & Gene & $\begin{array}{c}\text { log2 } \\
\text { (Fold Change) }\end{array}$ & $p$-value \\
\hline ENSG00000187134.14 & AKR1C1 & 2,8096 & $6,3 e-40$ & ENSG00000160211.19 & G6PD & 0,5086 & $2,07 e-09$ \\
\hline ENSG00000100292.17 & HMOX1 & 2,3832 & $2,9 e-150$ & ENSG00000138061.12 & CYP1B1 & 0,5078 & $4,6 e-11$ \\
\hline ENSG00000171658.8 & NMRAL2P & 1,6068 & $4,9 e-37$ & ENSG00000164400.6 & GPAT3 & 0,5013 & 0,0005 \\
\hline ENSG00000196139.14 & AKR1C3 & 1,3901 & $2,03 e-33$ & ENSG00000118496.5 & STC2 & 0,4940 & $5,01 e-10$ \\
\hline ENSG00000151012.13 & SLC7A11 & 1,3088 & $3,3 e-38$ & ENSG00000136810.13 & CSF2 & 0,4519 & 0,0002 \\
\hline ENSG00000108846.16 & $\mathrm{ABCC} 3$ & 1,2080 & $1,2 \mathrm{e}-31$ & ENSG00000157193.18 & FBXO30 & 0,4490 & 0,0001 \\
\hline ENSG00000181019.13 & NQO1 & 0,9812 & $1,6 e-37$ & ENSG00000154277.13 & TXN & 0,4484 & $4,09 \mathrm{e}-07$ \\
\hline ENSG00000087086.15 & FTL & 0,8993 & $4,4 \mathrm{e}-21$ & ENSG00000177156.11 & LRP8 & 0,4333 & $2,5 \mathrm{e}-06$ \\
\hline ENSG00000186529.16 & CYP4F3 & 0,8448 & $2,7 \mathrm{e}-09$ & ENSG00000163395.17 & UCHL1 & 0,4268 & $6,2 \mathrm{e}-07$ \\
\hline ENSG00000087842.11 & PIR & 0,8314 & $4,2 \mathrm{e}-14$ & ENSG00000161011.20 & TALDO1 & 0,4206 & $6,3 e-06$ \\
\hline ENSG00000001084.13 & GCLC & 0,7576 & $1,5 \mathrm{e}-16$ & ENSG00000167996.16 & IGFN1 & 0,4193 & 0,0002 \\
\hline ENSG00000171903.16 & CYP4F11 & 0,7492 & 0,0001 & ENSG00000120885.22 & SQSTM1 & 0,4120 & $1,9 e-06$ \\
\hline ENSG00000023909.10 & GCLM & 0,7390 & $1,05 e-17$ & ENSG00000132429.10 & FTH1 & 0,4098 & $1,2 \mathrm{e}-06$ \\
\hline ENSG00000108448.21 & TRIM16L & 0,7082 & $1,3 e-16$ & ENSG00000135919.14 & CLU & 0,4066 & 0,0003 \\
\hline ENSG00000172137.19 & CALB2 & 0,6737 & $5,1 \mathrm{e}-05$ & ENSG00000104687.14 & POPDC3 & 0,37602 & 0,0001 \\
\hline ENSG00000198431.16 & TXNRD1 & 0,6731 & $1,3 e-20$ & ENSG00000008394.13 & SERPINE2 & 0,3684 & $4,09 e-06$ \\
\hline ENSG00000115756.13 & HPCAL1 & 0,6729 & $1,1 \mathrm{e}-08$ & ENSG00000164543.7 & GSR & 0,3645 & $7,7 \mathrm{e}-05$ \\
\hline ENSG00000157150.5 & TIMP4 & 0,6634 & $2,1 e-05$ & ENSG00000111907.21 & MGST1 & 0,3636 & $9,2 \mathrm{e}-07$ \\
\hline ENSG00000167772.12 & ANGPTL4 & 0,6488 & $9,07 e-08$ & ENSG00000101236.17 & STK17A & 0,3631 & $1,04 \mathrm{e}-05$ \\
\hline ENSG00000085662.14 & AKR1B1 & 0,6444 & $4,3 e-13$ & ENSG00000143847.15 & TPD52L1 & 0,3616 & $1,9 e-05$ \\
\hline ENSG00000136231.14 & IGF2BP3 & 0,6251 & $1,7 \mathrm{e}-06$ & ENSG00000154127.10 & RNF24 & 0,3577 & $1,7 \mathrm{e}-05$ \\
\hline ENSG00000140961.14 & OSGIN1 & 0,6175 & $1,2 \mathrm{e}-07$ & ENSG00000168209.5 & PPFIA4 & 0,3516 & $3,3 e-05$ \\
\hline ENSG00000091490.11 & SEL1L3 & 0,6138 & $4,8 \mathrm{e}-13$ & ENSG00000221926.13 & UBASH3B & 0,3403 & $5,9 e-05$ \\
\hline ENSG00000073150.14 & PANX2 & 0,5810 & $5,3 e-09$ & ENSG00000136111.14 & DDIT4 & 0,3325 & $2,3 e-05$ \\
\hline ENSG00000198363.18 & $\mathrm{ASPH}$ & 0,5673 & $1,1 \mathrm{e}-13$ & ENSG00000072210.19 & TRIM16 & 0,3269 & 0,0002 \\
\hline ENSG00000059145.19 & UNKL & 0,5611 & $4,1 \mathrm{e}-09$ & ENSG00000104419.17 & TBC1D4 & 0,3247 & 0,0003 \\
\hline ENSG00000115919.15 & KYNU & 0,5560 & $1,7 \mathrm{e}-09$ & ENSG00000109854.13 & ALDH3A2 & 0,3066 & 0,0002 \\
\hline ENSG00000248323.7 & LUCAT1 & 0,5454 & $1,3 e-07$ & ENSG00000205336.13 & NDRG1 & 0,2987 & $3,1 \mathrm{e}-05$ \\
\hline ENSG00000163931.16 & TKT & 0,5353 & $4,9 e-09$ & ENSG00000211459.2 & HTATIP2 & 0,2873 & 0,0001 \\
\hline ENSG00000065833.9 & ME1 & 0,5283 & $1,3 e-10$ & ENSG00000138678.11 & ADGRG1 & 0,2827 & 0,0001 \\
\hline ENSG00000143819.12 & EPHX1 & 0,5233 & $1,9 e-05$ & ENSG00000113739.10 & MT-RNR1 & 0,2811 & 0,0001 \\
\hline
\end{tabular}


Table 3. List of the significantly downregulated genes in CaSki after exposure to I. cylindrica root extract

\begin{tabular}{|c|c|c|c|c|c|c|c|}
\hline Gene IDs & Gene name & $\begin{array}{c}\text { log2 (Fold } \\
\text { Change) }\end{array}$ & $p$-value & Gene IDs & Gene & $\begin{array}{c}\text { log2 (Fold } \\
\text { Change) }\end{array}$ & $p$-value \\
\hline ENSG00000162892 & IL24 & $-0,8532$ & $1,4 e-07$ & ENSG00000105141 & CASP14 & $-0,3960$ & 0,0001 \\
\hline ENSG00000115461 & IGFBP5 & $-0,8485$ & $2,3 e-32$ & ENSG00000107984 & DKK 1.00 & $-0,3871$ & 0,0005 \\
\hline ENSG00000283646 & LINC02009 & $-0,7919$ & $2,7 \mathrm{e}-08$ & ENSG00000233276 & GPX1 & $-0,3858$ & 0,0001 \\
\hline ENSG00000259953 & AL138756.1 & $-0,7271$ & $7,7 \mathrm{e}-11$ & ENSG00000118898 & PPL & $-0,3835$ & $8,2 \mathrm{e}-07$ \\
\hline ENSG00000232110 & AL353751.1 & $-0,7226$ & 0,0001 & ENSG00000044574 & HSPA5 & $-0,3818$ & $2,5 \mathrm{e}-07$ \\
\hline ENSG00000182898 & TCHHL1 & $-0,6257$ & 0,0001 & ENSG00000205413 & SAMD9 & $-0,3733$ & $3,2 e-05$ \\
\hline ENSG00000183287 & CCBE1 & $-0,6122$ & $4,7 e-10$ & ENSG00000166508 & MCM7 & $-0,3714$ & $1,7 \mathrm{e}-06$ \\
\hline ENSG00000234678 & ELF3-AS1 & $-0,6050$ & $2,9 e-05$ & ENSG00000099958 & DERL3 & $-0,3517$ & $9,9 e-05$ \\
\hline ENSG00000079337 & RAPGEF3 & $-0,5329$ & $5,7 \mathrm{e}-05$ & ENSG00000228742 & LINC02577 & $-0,3484$ & $4,8 \mathrm{e}-05$ \\
\hline ENSG00000102243 & VGLL1 & $-0,4843$ & $2,8 \mathrm{e}-06$ & ENSG00000041982 & TNC & $-0,3416$ & $7,4 \mathrm{e}-06$ \\
\hline ENSG00000146674 & IGFBP3 & $-0,4722$ & $7,3 e-11$ & ENSG00000011201 & ANOS1 & $-0,3415$ & 0,0002 \\
\hline ENSG00000150551 & LYPD1 & $-0,4711$ & $3,3 e-05$ & ENSG00000272398 & CD24 & $-0,3389$ & $5,7 e-06$ \\
\hline ENSG00000206337 & HCP5 & $-0,4711$ & $7,5 e-05$ & ENSG00000204941 & PSG5 & $-0,3368$ & $1,6 e-05$ \\
\hline ENSG00000260604 & AL590004.3 & $-0,4677$ & $5,1 \mathrm{e}-06$ & ENSG00000172296 & SPTLC3 & $-0,3349$ & 0,0002 \\
\hline ENSG00000117318 & ID3 & $-0,4652$ & $1,7 \mathrm{e}-06$ & ENSG00000050405 & LIMA1 & $-0,3282$ & $3,1 \mathrm{e}-06$ \\
\hline ENSG00000171346 & KRT15 & $-0,4631$ & $2,3 e-06$ & ENSG00000165312 & OTUD1 & $-0,3248$ & 0,0003 \\
\hline ENSG00000179218 & CALR & $-0,4512$ & $1,4 \mathrm{e}-07$ & ENSG00000159423 & ALDH4A1 & $-0,3238$ & 0,0005 \\
\hline ENSG00000162496 & DHRS3 & $-0,4449$ & $7,5 e-06$ & ENSG00000265972 & TXNIP & $-0,3233$ & $2,9 e-05$ \\
\hline ENSG00000116774 & OLFML3 & $-0,4389$ & 0,0002 & ENSG00000143878 & $\mathrm{RHOB}$ & $-0,3214$ & $3,5603 e-05$ \\
\hline ENSG00000119922 & IFIT2 & $-0,4363$ & 0,0004 & ENSG00000112139 & MDGA1 & $-0,3114$ & 0,0002 \\
\hline ENSG00000180914 & OXTR & $-0,4344$ & $6,8 \mathrm{e}-07$ & ENSG00000189060 & $\mathrm{H} 1-0$ & $-0,2963$ & $5,1 \mathrm{e}-05$ \\
\hline ENSG00000128510 & CPA4 & $-0,4342$ & 0,0002 & ENSG00000112902 & SEMA5A & $-0,2897$ & 0,0002 \\
\hline ENSG00000137312 & FLOT1 & $-0,4300$ & $1,6 \mathrm{e}-05$ & ENSG00000167767 & KRT80 & $-0,2852$ & 0,0001 \\
\hline ENSG00000186847 & KRT14 & $-0,4298$ & $4,3 e-06$ & ENSG00000172379 & ARNT2 & $-0,2780$ & 0,0003 \\
\hline ENSG00000127084 & FGD3 & $-0,4280$ & $1,8 \mathrm{e}-05$ & ENSG00000124766 & SOX4 & $-0,2716$ & 0,0004 \\
\hline ENSG00000166689 & PLEKHA7 & $-0,4212$ & $1,04 \mathrm{e}-07$ & ENSG00000166598 & HSP90B1 & $-0,2687$ & 0,0003 \\
\hline ENSG00000091986 & CCDC80 & $-0,4206$ & $2,1 \mathrm{e}-09$ & ENSG00000163430 & FSTL1 & $-0,2686$ & 0,0001 \\
\hline ENSG00000243137 & PSG4 & $-0,4101$ & $5,5 \mathrm{e}-06$ & ENSG00000135842 & NIBAN1 & $-0,2642$ & 0,0003 \\
\hline ENSG00000265107 & GJA5 & $-0,3963$ & $3,6 e-05$ & ENSG00000115414 & FN1 & $-0,2394$ & 0,0004 \\
\hline
\end{tabular}

